\title{
Image-Enhanced Endoscopy in Lower Gastrointestinal Diseases: Present and Future
}

\author{
Han Hee Lee ${ }^{1,2}$ and Bo-In Lee $e^{1,2}$ \\ ${ }^{1}$ Division of Gastroenterology, Department of Internal Medicine, College of Medicine, The Catholic University of Korea, Seoul, \\ ${ }^{2}$ Catholic Photomedicine Research Institute, Seoul, Korea
}

From dye-assisted conventional chromoendoscopy to novel virtual chromoendoscopy, image-enhanced endoscopy (IEE) is continuously evolving to meet clinical needs and improve the quality of colonoscopy. Dye-assisted chromoendoscopy using indigo carmine or crystal violet, although slightly old-fashioned, is still useful to emphasize the pit patterns of the colonic mucosa and predict the histological structures of relevant lesions. Equipment-based virtual chromoendoscopy has the advantage of being relatively easy to use. There are several types of virtual chromoendoscopy that vary depending on the manufacturer and operating principle. IEE plays distinctive roles with respect to histologic characterization of colorectal polyps and prediction of the invasion depth of colorectal cancers. In addition, the newest models of IEE have the potential to increase adenoma and polyp detection rates in screening colonoscopy.

Clin Endosc 2018;51:534-540

Key Words: Image enhancement; Colonoscopy; Narrow-band imaging; Colorectal polyp

\section{INTRODUCTION}

Improving the quality of screening colonoscopy is key to detecting adenomas and preventing colorectal cancer. If polyps are found during screening colonoscopies, distinguishing between non-neoplastic and neoplastic lesions can improve the efficiency of the colonoscopy and reduce unnecessary resection. When a malignant lesion is encountered, prediction of the depth of invasion can help decide whether to perform endoscopic resection or surgery. To meet these clinical needs, image-enhanced endoscopy (IEE), including dye-assisted conventional chromoendoscopy and virtual chromoendoscopy, is continually evolving. In this review, we summarize the types

Received: October 19, 2018 Revised: November 14, 2018

Accepted: November 14, 2018

Correspondence: Bo-In Lee

Division of Gastroenterology, Department of Internal Medicine, Seoul St. Mary's Hospital, College of Medicine, The Catholic University of Korea, 222 Banpo-daero, Seocho-gu, Seoul 06591, Korea

Tel: +82-2-2258-2044, Fax: +82-2-2258-2089, E-mail: gidoc4u@gmail.com ORCID: https://orcid.org/0000-0002-0218-4136

(cc) This is an Open Access article distributed under the terms of the Creative Commons Attribution Non-Commercial License (http://creativecommons.org/ licenses/by-nc/3.0) which permits unrestricted non-commercial use, distribution, and reproduction in any medium, provided the original work is properly cited. and characteristics of existing IEE techniques and discuss the current clinical usefulness and future prospects of IEE.

\section{DYE-ASSISTED CONVENTIONAL CHROMOENDOSCOPY}

Conventional chromoendoscopy is a classical procedure that can be performed only with standard endoscopy. A pit, an orifice of the colonic crypt, is observed in the colonic mucosa and shows specific arrangements in different types of lesions, referred to as the pit pattern. The visualization of the pit pattern of the colonic mucosa can be enhanced by application of a dye.

Indigo carmine is the most widely used dye in conventional chromoendoscopy. It is a contrast dye that is not absorbed by the mucosal glands and that stains depressed areas, including mucosal pits and grooves. A diluted solution ( $0.1 \%$ to $0.5 \%)$ of indigo carmine is most often used. It can be sprayed directly onto the colonic mucosa through the working channel of the endoscope or with a dye-spray catheter.

Crystal violet is an absorptive dye that stains epithelial cells in the colonic mucosal glands, making the pit looks 
white after dyeing. It is generally used at a concentration of $0.05 \%$. After spraying onto the colonic mucosa, staining takes 2-3 minutes.

Pit-pattern characterization using a magnifying colonoscope follows Kudo's classification. This classification categorizes the pit pattern into six groups: types I, II, $\mathrm{III}_{\mathrm{L}}, \mathrm{III}_{\mathrm{S}}$, IV, and V (Fig. 1). Type I has pits of normal mucosa that are round and regular in size and arrangement. Type II has pits of hyperplastic polyps that are star-shaped or onion-like and regularly arranged. Types I and II are classified as non-neoplastic lesions. Types III and IV are classified as adenomatous lesions. Type $\mathrm{III}_{\mathrm{L}}$ shows elongated pits that usually reflect tubular adenoma with low-grade dysplasia. Type $\mathrm{III}_{\mathrm{S}}$ shows compactly arranged pits that are smaller than normal pits, indicating tubular adenoma with high-grade dysplasia or intramucosal cancer. Type IV has branched pits of villous adenoma. Type $\mathrm{V}$ is classified as a cancerous lesion and is divided into two subtypes: type $V_{I}$ (irregular) and type $\mathrm{V}_{\mathrm{N}}$ (non-structural). Type $\mathrm{V}_{\mathrm{I}}$ is observed in both invasive and non-invasive cancers, whereas type $V_{N}$ strongly suggests deep submucosal cancers. Thus, pit patterns are useful in assessing on the histological structures of a lesion (Fig. 2).

\section{VIRTUAL CHROMOENDOSCOPY}

Although conventional chromoendoscopy has advantages over standard colonoscopy, the procedure is more complicated than equipment-based virtual chromoendoscopy. Endoscopists can easily perform virtual chromoendoscopy through single-button operation. Virtual chromoendoscopy is used to observe the capillaries of the lesion and the mucosal epitheli-
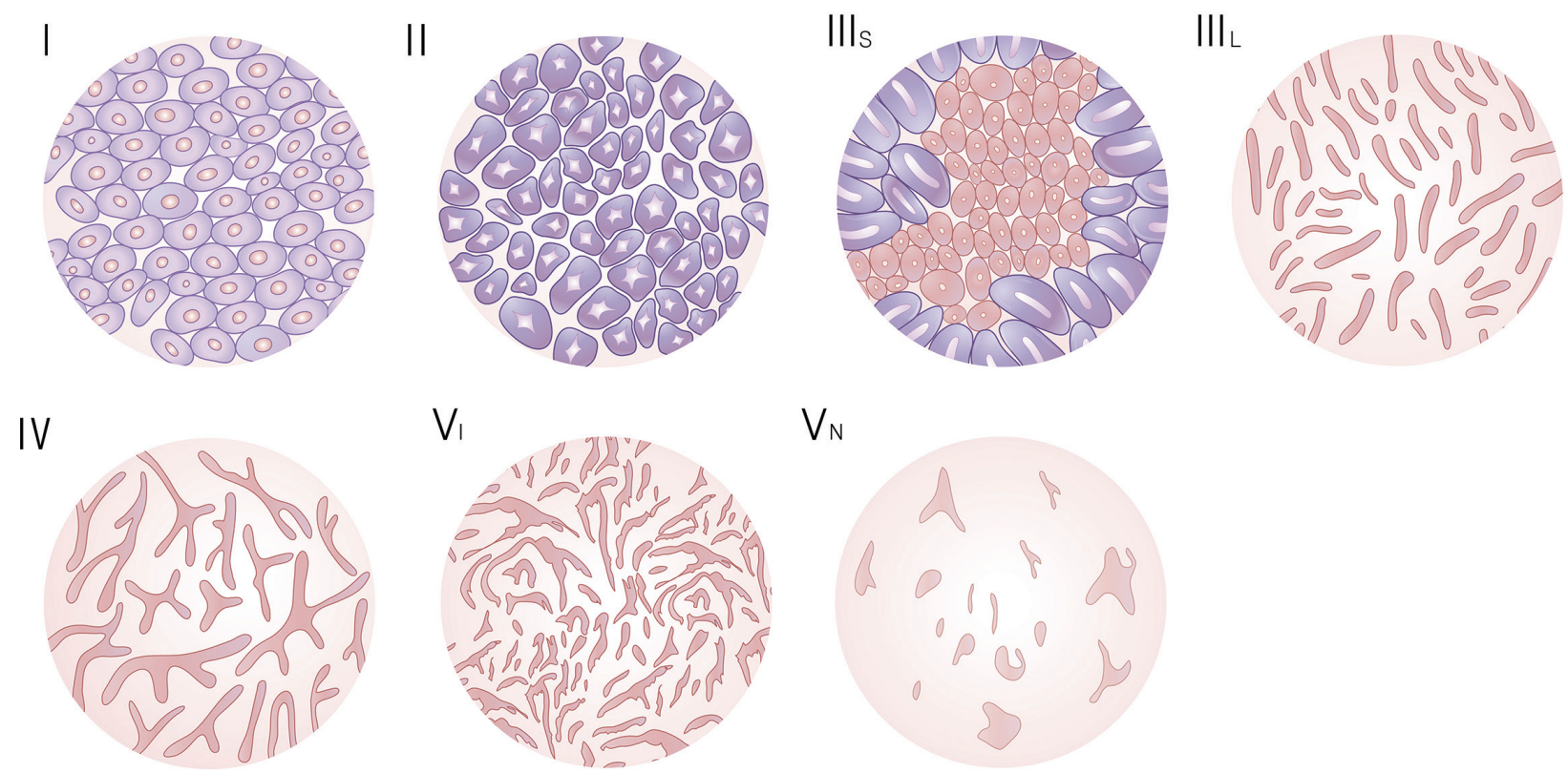

Fig. 1. Schematic presentation of Kudo's pit-pattern classification.
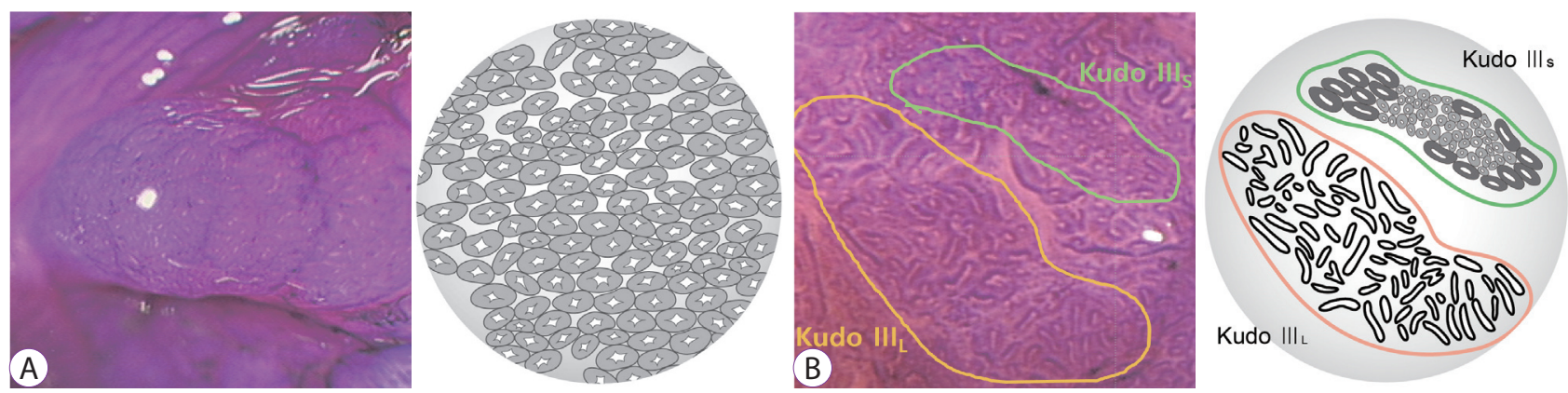

Fig. 2. Prediction of the histological structure of the detected lesion by magnifying chromoendoscopy using crystal violet. (A) The pits of the polyp appear to be pressed flat, and they are regularly arranged. This pit-pattern is similar to Kudo's type II pattern, which suggests a hyperplastic polyp. (B) The pit-pattern of the lesion shows a mixed pattern of Kudo's types III $\mathrm{L}$ and III . This lesion was confirmed as being an intraepithelial adenocarcinoma. 
um of the microstructure.

\section{Narrow-band imaging}

The conventional red/green/blue gastrointestinal endoscope system has 3 broadband optical filters covering the visible wavelength range from 400 to $800 \mathrm{~nm}$. The narrow-band imaging (NBI) system has two narrow-band illuminations of $415 \mathrm{~nm}$ and $540 \mathrm{~nm}$ using a special optical filter. ${ }^{2}$ Because mucosal hemoglobin selectively absorbs $415-\mathrm{nm}$ blue light, thin capillary vessels can be seen most clearly at this wavelength. On using this narrow spectrum, the contrast of the microvascular structure on the surface of the lesions is markedly improved. ${ }^{3}$

Although pit pattern characterization was almost standardized by Kudo's classification, there are a variety of NBI magnifying observation classifications for colorectal tumors.

In 2009, Sano et al. reported the first NBI classification of the capillary pattern (CP) using magnifying colonoscopy. ${ }^{4}$ In Sano's classification, the CP is described as the arrangement of the meshed capillary surrounding a pit. $\mathrm{CP}$ was classified into three different types (CP types I, II, and IIIA/B). Assessment of CP by magnifying NBI is simple and reliable for differentiating colorectal non-neoplastic from colorectal neoplastic polyps, depending on the presence of meshed capillary vessels. ${ }^{4}$ It has great accuracy in differentiating between low-grade dysplasia and high-grade dysplasia/invasive cancer depending on the regularity of the existing meshed capillary vessels. ${ }^{5}$ Identification of CP types IIIA and IIIB is also useful for predicting the invasion depth of early colorectal neoplasms. ${ }^{6}$

The Hiroshima classification, published in 2008, comprehensively evaluates both the pit-like surface pattern and $\mathrm{CP}$ on NBI magnifying endoscopy. ${ }^{7}$ Types A, B and C are categorized according to the regularity of the surface pattern. Type $\mathrm{C}$ is subclassified into categories C1-C3 according to the heterogeneity of the vascular diameter and distribution. The positive predictive value of type C3 for the diagnosis of carcinomas with massive submucosal invasion was $100 \%$.
The Showa classification, proposed in 2009, is a more intuitive classification that is based on morphological characteristics. ${ }^{8}$ This classification includes a total of 6 categories: normal, faint, network, dense, irregular, and sparse patterns. Irregular and sparse patterns are presumed to suggest massively invasive submucosal cancer.

The NBI International Colorectal Endoscopic (NICE) classification was proposed in 2009 as a simple international NBI endoscopic classification for colorectal tumors (Table 1). The NICE classification is based on the color, vessels, and surface pattern of the colorectal tumors observed on non-magnifying endoscopy. International validation studies have demonstrated the usefulness of the NICE classification in diagnosing colorectal polyp histology and predicting deep submucosal invasion of carcinomas. ${ }^{9,10}$ The Japan NBI Expert Team classification was proposed in 2014 after selected NBI specialists reached a consensus on establishing a universal NBI magnifying endoscopic classification (Table 2). ${ }^{11}$

\section{Fuji intelligent color enhancement, blue light imag- ing, and linked color imaging}

Fuji intelligent color enhancement (FICE) is a computed spectral estimation technology that emphasizes subtle mucosal changes through reconstruction of certain wavelengths. Unlike NBI, it has a processing system instead of optical filter for adjusting wavelength. FICE can process the captured images according to the most appropriate wavelength for examination. However, most prospective randomized studies failed to demonstrate that FICE improves the adenoma detection rate $(\mathrm{ADR})$ or miss rate in comparison with white light endoscopy (WLE). ${ }^{12-14}$

Blue light imaging (BLI) is a new IEE system released by Fujifilm. ${ }^{15,16}$ It focuses on the characteristics of short wavelength absorption of hemoglobin (at $410 \mathrm{~nm}$ ) combined with specific white light spectral colors. It uses a new high-performance 4-LED multi-light system as the light source instead of

Table 1. Narrow-Band Imaging International Colorectal Endoscopic Classification

\begin{tabular}{llll}
\hline & \multicolumn{1}{c}{ Type I } & Type II & Type III \\
\hline Color & Same or lighter than background & $\begin{array}{c}\text { Browner relative to background } \\
\text { (verify color arises from vessels) }\end{array}$ & $\begin{array}{c}\text { Brown to dark brown relative to } \\
\text { background; sometimes patchy } \\
\text { whiter areas }\end{array}$ \\
Vessels & $\begin{array}{l}\text { None, or isolated lacy vessels might } \\
\text { be present coursing across the } \\
\text { lesion }\end{array}$ & $\begin{array}{c}\text { Thick brown vessels surrounding } \\
\text { white structures }\end{array}$ & $\begin{array}{c}\text { Has area(s) with markedly distort- } \\
\text { ed or missing vessels }\end{array}$ \\
$\begin{array}{l}\text { Surface } \\
\text { pattern }\end{array}$ & $\begin{array}{l}\text { size, or homogenous absence of } \\
\text { pattern }\end{array}$ & $\begin{array}{c}\text { Oval, tubular or branched white } \\
\text { structures surrounded by brown } \\
\text { vessels }\end{array}$ & $\begin{array}{c}\text { Areas of distortion or absence of } \\
\text { pattern }\end{array}$ \\
Most likely pathology & Hyperplastic & Adenoma & Deep submucosal invasive cancer \\
\hline
\end{tabular}


xenon light. This system generates brighter images than those obtained on using xenon light, which enhances the visibility of both the microvascular and superficial mucosal patterns. Therefore, mucosal surface images become clearer.

Linked color imaging (LCI) was developed on the basis of the BLI technique. Although BLI has brighter endoscopic views than xenon-lamp-based IEE, the images are still darker than those obtained from white light imaging (WLI), which can result in low diagnostic rates. To overcome this, LCI utilizes additional red-wavelength information compared with BLI. ${ }^{17}$ Therefore, LCI is able to produce images of sufficient brightness and that are similar to those produced by WLI. Furthermore, LCI enhances the differences in the red color spectrum because the increased contrast in red color leads to lesions being more easily identified under endoscopy. A red color discovered in purple color is the key finding for detection.

\section{i-Scan}

i-Scan uses a post-processing filter technology similar to that of FICE. It generates high-definition images using three image enhancement modes: contrast enhancement, surface enhancement, and tone enhancement. The study results of i-Scan are conflicting. Of two randomized prospective studies, one reported that high-definition colonoscopy with i-Scan is better than standard video colonoscopy in detecting colorectal neoplastic lesions, ${ }^{18}$ whereas the other demonstrated that i-Scan did not improve the ADR and failed to prevent missed polyps compared with high-definition WLE. ${ }^{18,19}$

\section{CLINICAL APPLICATIONS OF IEE}

\section{Detection of colorectal polyps}

Dye-assisted conventional chromoendoscopy may increase the detection of colorectal polyps. In a systematic review and meta-analysis including seven randomized controlled trials comparing polyp detection in patients assigned to white light colonoscopy or dye-assisted chromoendoscopy, dye-assisted chromoendoscopy was significantly preferred for all detection outcomes. ${ }^{20}$ However, pancolonic chromoendoscopy takes much more time and effort. Considering that the mean withdrawal times were much longer in the chromoendoscopy group than in the WLE group, the improvement in the polyp detection rate (PDR) may be because of the increased observation time rather than the dye. ${ }^{21}$ Thus, pancolonic chromoendoscopy might not be beneficial for routine application.

Virtual chromoendoscopy also showed no definite benefits in the detection of colorectal polyps or adenomas. Several meta-analyses comparing NBI with WLE in the detection of colorectal adenomas showed there was no significant difference in ADR between these two modalities. ${ }^{22-26}$ FICE/i-Scan also demonstrated no benefit over WLE in a meta-analysis including five randomized studies. ${ }^{26}$

The novel NBI system with near focus might be better for polyp and adenoma detection. This new generation NBI using the 190 (Exera) or 290 (Lucera) system provides two-fold brighter images in full high-definition, compared with the old version. ${ }^{27}$ This new NBI showed significantly increased ADR and PDR compared with high-definition WLE. ${ }^{28}$

Table 2. Japan Narrow-Band Imaging Expert Team Classification

\begin{tabular}{|c|c|c|c|c|}
\hline & Type 1 & Type $2 \mathrm{~A}$ & Type 2B & Type 3 \\
\hline Vessel pattern & • Invisible & $\begin{array}{l}\text { - Regular caliber } \\
\text { - Regular distribution } \\
\text { (meshed/spiral pattern) }\end{array}$ & $\begin{array}{l}\text { - Variable caliber } \\
\text { - Irregular distribution }\end{array}$ & $\begin{array}{l}\text { - Loose vessel areas } \\
\text { - Interruption of thick ves- } \\
\text { sels }\end{array}$ \\
\hline $\begin{array}{l}\text { Surface } \\
\text { pattern }\end{array}$ & $\begin{array}{l}\text { - Regular dark or white } \\
\text { spots } \\
\text { - Similar to surrounding } \\
\text { normal mucosa }\end{array}$ & $\begin{array}{l}\text { - Regular (tubular/ } \\
\text { branched/papillary) }\end{array}$ & - Irregular or obscure & - Amorphous areas \\
\hline $\begin{array}{l}\text { Most likely } \\
\text { pathology }\end{array}$ & $\begin{array}{l}\text { Hyperplastic polyp/Sessile } \\
\text { serrated polyp }\end{array}$ & $\begin{array}{l}\text { Low grade intramucosal } \\
\text { neoplasia }\end{array}$ & $\begin{array}{l}\text { High grade intramucosal } \\
\text { neoplasia/Shallow submu- } \\
\text { cosal invasive cancer }\end{array}$ & $\begin{array}{l}\text { Deep submucosal } \\
\text { invasive cancer }\end{array}$ \\
\hline Schema & 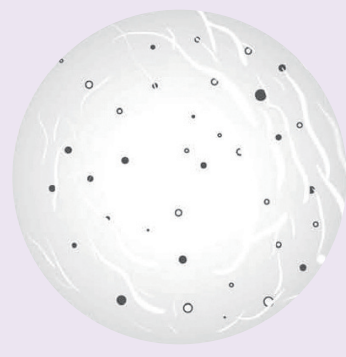 & (1) & & \\
\hline
\end{tabular}


There are limited studies on BLI and LCI because these modalities were only recently released. In one study, BLI bright mode was found to improve the visibility of colonic lesions compared to that on WLI. ${ }^{29}$ In addition, colonoscopies using BLI resulted in lower colon adenoma miss rates than those using WLI in a recent randomized tandem trial. ${ }^{30} \mathrm{LCI}$ increases the visibility of flat lesions such as sessile serrated polyps and improves the detection rate of these types of lesions. ${ }^{31}$

\section{Polyp characterization}

As previously stated, NBI differentiates neoplastic and non-neoplastic polyps by enhancing mucosal vasculature and surface patterns. FICE and i-Scan also emphasize the mucosal pattern of polyps by reconstructing images at different wavelengths using spectral estimation technology. Meta-analysis proved that these three endoscopic imaging techniques have reliable rates of sensitivity, specificity, and negative predictivity in the differentiation of non-neoplastic and neoplastic colorectal lesions when they are used by appropriately trained endoscopists. ${ }^{32}$ These results have enabled endoscopists to speculate the histopathological type of colorectal polyps in vivo and allowed them to discard diminutive polyps after resection, reducing the costs of histological analysis. ${ }^{33}$

The diagnostic effectiveness of BLI magnification for the diagnosis of colorectal neoplasms is comparable to that of NBI magnification. ${ }^{34}$

Table 3. Criteria for Deep Submucosal Colorectal Cancer by Image-Enhanced Endoscopy

\begin{tabular}{lc}
\hline Type of IEE/Classification & Criteria \\
\hline Dye-based chromoendoscopy & \\
Kudo's pit pattern & $\mathrm{V}_{\mathrm{I}}+$ demarcated area, $\mathrm{V}_{\mathrm{N}}{ }^{36}$ \\
Virtual chromoendoscopy & \\
Sano & $\mathrm{IIIB}^{4}$ \\
Hiroshima & $\mathrm{C}^{7}$ \\
Showa & Sparse or Irregular \\
NICE & $3^{10}$ \\
JNET & $2 \mathrm{~B}-$ high, $3^{11}$ \\
\hline
\end{tabular}

IEE, image-enhanced endoscopy; NICE, narrow-band imaging international colorectal endoscopic; JNET, Japan narrow-band imaging expert team.
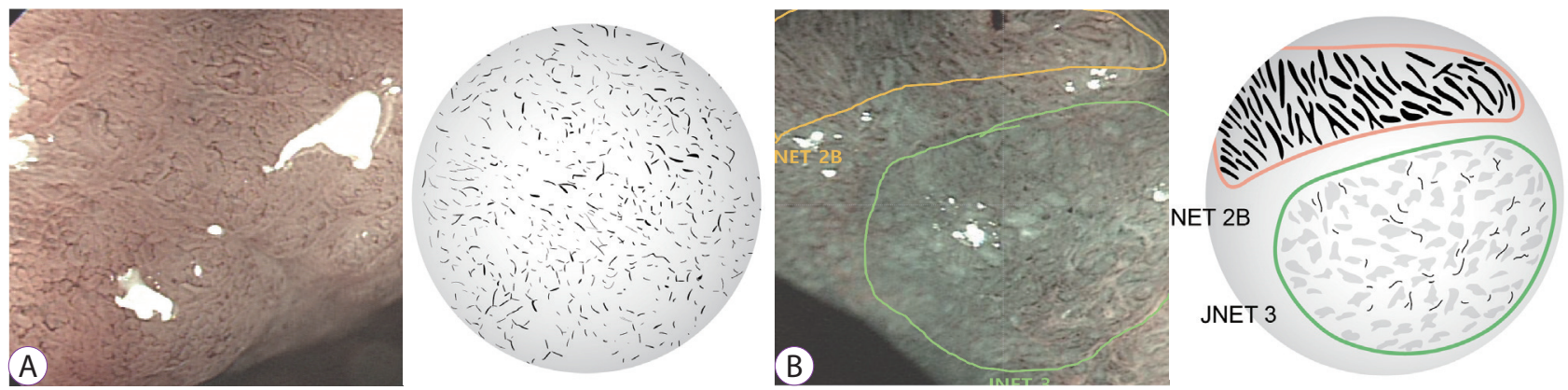

Fig. 3. Prediction of the invasion depth of the detected lesion by magnifying narrow-band imaging. (A) The lesion shows a capillary pattern characterized by a blind ending, lack of uniformity, and curtailed irregularly, which is similar to the Sano IIIA pattern. This lesion was confirmed as being an intraepithelial adenocarcinoma. (B) The slightly depressed center of the lesion shows loose vessel areas and an amorphous surface pattern. This lesion was confirmed as being a deep submucosal invasive adenocarcinoma.

\begin{tabular}{|c|c|c|c|}
\hline 1st step & \multicolumn{2}{|c|}{ 2nd step } & 3rd step \\
\hline $\begin{array}{c}\text { Conventional } \\
\text { colonoscopy }\end{array}$ & \multicolumn{2}{|c|}{$\begin{array}{l}\text { NBI as virtual chromoendoscopy } \\
\text { (CP) }\end{array}$} & $\begin{array}{c}\text { Dye-assisted } \\
\text { chromoendoscopy }\end{array}$ \\
\hline \multirow{2}{*}{ Identification of lesion } & $\begin{array}{l}\text { CP: type I } \\
\text { CP: type II, IIIA with } \\
\text { demarcated area }\end{array}$ & $\begin{array}{l}\text { Follow up } \\
\text { Endoscopic resection }\end{array}$ & \\
\hline & $\begin{array}{l}\text { CP: type IIIB and IIIA with } \\
\text { demarcated area } \\
\text { Surface pattern }(+) \\
\text { Surface pattern }(-)\end{array}$ & $\begin{array}{l}\text { 3rd step } \\
\text { Surgery highly recommend }\end{array}$ & $\begin{array}{l}\mathrm{V}_{\mathrm{I}} \text { (noninvasive) } \\
\rightarrow \text { Endoscopic resection } \\
\mathrm{V}_{\mathrm{I}} \text { (invasive) }+\mathrm{V}_{\mathrm{N}} \\
\rightarrow \text { Surgery }\end{array}$ \\
\hline
\end{tabular}

Fig. 4. Three-step strategy of narrow-band imaging (NBI) colonoscopy. CP, capillary pattern. 


\section{Prediction of the depth of invasion}

With the recent rapid development of endoscopic treatments, endoscopic submucosal dissection (ESD) has become an important minimally invasive treatment for early colorectal cancer. ${ }^{35}$ To decide whether to perform surgery or ESD, it is essential to make an accurate endoscopic prediction of the depth of invasion.

As stated earlier in this review, IEE can also help predict the invasion depth of colorectal cancer. Magnifying chromoendoscopy with crystal violet or indigo carmine can identify the neoplastic invasive pattern, which is defined as Kudo's type $V_{I}$ with a demarcated area and type $\mathrm{V}_{\mathrm{N} \cdot}{ }^{36}$ Determination of an invasive pattern by this method is highly effective in differentiating superficial or intramucosal submucosal cancers $(<1,000$ $\mu \mathrm{m})$ from deep submucosal cancers $(\geq 1,000 \mu \mathrm{m})$. Variable classifications of NBI can also predict the depth of invasion (Fig. 3). We have summarized the criteria for deep submucosal cancer by IEE in Table 3.

On the basis of the capability of predicting the invasiveness of colonic lesions by IEE, a three-step strategy for management of these lesions has been suggested (Fig. 4). ${ }^{37}$ The first step is to identify the lesion by conventional colonoscopy. The second step is to observe capillary and surface patterns of the identified lesion by NBI. The third step is to examine the pit pattern of the lesion by dye-assisted chromoendoscopy.

LCI high-magnification colonoscopy combined with crystal violet staining is expected to enhance the accuracy of endoscopic prediction of invasion depth in early-stage colorectal cancer. $^{38}$

\section{CONCLUSIONS}

Colorectal cancer screening programs are increasing worldwide, increasing the importance of high-quality colonoscopies. IEE plays distinctive roles in the histologic characterization of colorectal polyps and prediction of the invasion depth of colorectal cancers. The latest advancements in IEE, such as new-generation NBI, BLI, or LCI, have the potential for increasing $\mathrm{ADR}$ and $\mathrm{PDR}$ in screening colonoscopy. More robust and rigorous clinical trials must be conducted to support the routine use of IEE for screening average-risk populations. In addition, efforts to educate and train community-based gastroenterologists who are not familiar with IEE on the IEE technique should be continued.

\section{Conflicts of Interest}

The authors have no financial conflicts of interest.

\section{Acknowledgements}

This research was supported by the Bio \& Medical Technology Development Program of the National Research Foundation (NRF) funded by the Ministry of Science \& ICT (NRF-2018M3A9E8021507).

\section{REFERENCES}

1. Kudo S, Rubio CA, Teixeira CR, Kashida H, Kogure E. Pit pattern in colorectal neoplasia: endoscopic magnifying view. Endoscopy 2001;33:367373.

2. Muto M, Horimatsu T, Ezoe Y, Morita S, Miyamoto S. Improving visualization techniques by narrow band imaging and magnification endoscopy. J Gastroenterol Hepatol 2009;24:1333-1346.

3. Gono K, Obi T, Yamaguchi M, et al. Appearance of enhanced tissue features in narrow-band endoscopic imaging. J Biomed Opt 2004;9:568577.

4. Sano Y, Ikematsu H, Fu KI, et al. Meshed capillary vessels by use of narrow-band imaging for differential diagnosis of small colorectal polyps. Gastrointest Endosc 2009;69:278-283.

5. Katagiri A, Fu KI, Sano Y, et al. Narrow band imaging with magnifying colonoscopy as diagnostic tool for predicting histology of early colorectal neoplasia. Aliment Pharmacol Ther 2008;27:1269-1274.

6. Ikematsu H, Matsuda T, Emura F, et al. Efficacy of capillary pattern type IIIA/IIIB by magnifying narrow band imaging for estimating depth of invasion of early colorectal neoplasms. BMC Gastroenterol 2010;10:33.

7. Kanao H, Tanaka S, Oka S, Hirata M, Yoshida S, Chayama K. Narrow-band imaging magnification predicts the histology and invasion depth of colorectal tumors. Gastrointest Endosc 2009;69(3 Pt 2):631-636.

8. Wada Y, Kudo SE, Kashida H, et al. Diagnosis of colorectal lesions with the magnifying narrow-band imaging system. Gastrointest Endosc 2009; 70:522-531.

9. Hewett DG, Kaltenbach T, Sano Y, et al. Validation of a simple classification system for endoscopic diagnosis of small colorectal polyps using narrow-band imaging. Gastroenterology 2012;143:599-607.e1.

10. Hayashi N, Tanaka S, Hewett DG, et al. Endoscopic prediction of deep submucosal invasive carcinoma: validation of the narrow-band imaging international colorectal endoscopic (NICE) classification. Gastrointest Endosc 2013;78:625-632.

11. Sano Y, Tanaka S, Kudo SE, et al. Narrow-band imaging (NBI) magnifying endoscopic classification of colorectal tumors proposed by the Japan NBI expert team. Dig Endosc 2016;28:526-533.

12. Pohl J, Lotterer E, Balzer C, et al. Computed virtual chromoendoscopy versus standard colonoscopy with targeted indigocarmine chromoscopy: a randomised multicentre trial. Gut 2009;58:73-78.

13. Aminalai A, Rösch $\mathrm{T}$, Aschenbeck J, et al. Live image processing does not increase adenoma detection rate during colonoscopy: a randomized comparison between FICE and conventional imaging (Berlin colonoscopy project 5, BECOP-5). Am J Gastroenterol 2010;105:2383-2388.

14. Chung SJ, Kim D, Song JH, et al. Efficacy of computed virtual chromoendoscopy on colorectal cancer screening: a prospective, randomized, back-to-back trial of Fuji intelligent color enhancement versus conventional colonoscopy to compare adenoma miss rates. Gastrointest Endosc 2010;72:136-142.

15. Osawa H, Yamamoto H. Present and future status of flexible spectral imaging color enhancement and blue laser imaging technology. Dig Endosc 2014;26 Suppl 1:105-115.

16. Rondonotti E, Paggi S, Amato A, et al. Blue-light imaging compared with high-definition white light for real-time histology prediction of colorectal polyps less than 1 centimeter: a prospective randomized study. Gastrointest Endosc 2018 Sep 28 [Epub]. https://doi.org/10.1016/ j.gie.2018.09.027.

17. Sun X, Dong T, Bi Y, et al. Linked color imaging application for improving 
the endoscopic diagnosis accuracy: a pilot study. Sci Rep 2016;6:33473.

18. Hoffman A, Sar F, Goetz M, et al. High definition colonoscopy combined with i-Scan is superior in the detection of colorectal neoplasias compared with standard video colonoscopy: a prospective randomized controlled trial. Endoscopy 2010;42:827-833.

19. Hong SN, Choe WH, Lee JH, et al. Prospective, randomized, back-toback trial evaluating the usefulness of i-Scan in screening colonoscopy. Gastrointest Endosc 2012;75:1011-1021.e2.

20. Brown SR, Baraza W, Din S, Riley S. Chromoscopy versus conventional endoscopy for the detection of polyps in the colon and rectum. Cochrane Database Syst Rev 2016;4:CD006439.

21. Brooker JC, Saunders BP, Shah SG, et al. Total colonic dye-spray increases the detection of diminutive adenomas during routine colonoscopy: a randomized controlled trial. Gastrointest Endosc 2002;56:333-338.

22. Jin XF, Chai TH, Shi JW, Yang XC, Sun QY. Meta-analysis for evaluating the accuracy of endoscopy with narrow band imaging in detecting colorectal adenomas. J Gastroenterol Hepatol 2012;27:882-887.

23. Dinesen L, Chua TJ, Kaffes AJ. Meta-analysis of narrow-band imaging versus conventional colonoscopy for adenoma detection. Gastrointest Endosc 2012;75:604-611.

24. Nagorni A, Bjelakovic G, Petrovic B. Narrow band imaging versus conventional white light colonoscopy for the detection of colorectal polyps. Cochrane Database Syst Rev 2012;1:CD008361.

25. Pasha SF, Leighton JA, Das A, et al. Comparison of the yield and miss rate of narrow band imaging and white light endoscopy in patients undergoing screening or surveillance colonoscopy: a meta-analysis. Am J Gastroenterol 2012;107:363-370; quiz 371.

26. Omata F, Ohde S, Deshpande GA, Kobayashi D, Masuda K, Fukui T. Image-enhanced, chromo, and cap-assisted colonoscopy for improving adenoma/neoplasia detection rate: a systematic review and meta-analysis. Scand J Gastroenterol 2014;49:222-237.

27. Rey JF, Tanaka S, Lambert R, Tajiri H. Evaluation of the clinical outcomes associated with EXERA II and LUCERA endoscopes. Dig Endosc 2009;21 Suppl 1:S113-S120.

28. Leung WK, Lo OS, Liu KS, et al. Detection of colorectal adenoma by narrow band imaging (HQ190) vs. high-definition white light colonoscopy: a randomized controlled trial. Am J Gastroenterol 2014;109:855863.

29. Yoshida N, Hisabe T, Hirose R, et al. Improvement in the visibility of colorectal polyps by using blue laser imaging (with video). Gastrointest Endosc 2015;82:542-549.

30. Shimoda R, Sakata Y, Fujise T, et al. The adenoma miss rate of blue-laser imaging vs. white-light imaging during colonoscopy: a randomized tandem trial. Endoscopy 2017;49:186-190.

31. Suzuki T, Hara T, Kitagawa Y, et al. Linked-color imaging improves endoscopic visibility of colorectal nongranular flat lesions. Gastrointest Endosc 2017;86:692-697.

32. Wanders LK, East JE, Uitentuis SE, Leeflang MM, Dekker E. Diagnostic performance of narrowed spectrum endoscopy, autofluorescence imaging, and confocal laser endomicroscopy for optical diagnosis of colonic polyps: a meta-analysis. Lancet Oncol 2013;14:1337-1347.

33. Hassan C, Pickhardt PJ, Rex DK. A resect and discard strategy would improve cost-effectiveness of colorectal cancer screening. Clin Gastroenterol Hepatol 2010;8:865-869, 869.el-e3.

34. Yoshida N, Hisabe T, Inada Y, et al. The ability of a novel blue laser imaging system for the diagnosis of invasion depth of colorectal neoplasms. J Gastroenterol 2014;49:73-80.

35. Nakajima T, Saito Y, Tanaka S, et al. Current status of endoscopic resection strategy for large, early colorectal neoplasia in Japan. Surg Endosc 2013;27:3262-3270

36. Matsuda T, Fujii T, Saito Y, et al. Efficacy of the invasive/non-invasive pattern by magnifying chromoendoscopy to estimate the depth of invasion of early colorectal neoplasms. Am J Gastroenterol 2008;103:27002706.

37. Iwatate M, Ikumoto T, Hattori S, Sano W, Sano Y, Fujimori T. NBI and NBI combined with magnifying colonoscopy. Diagn Ther Endosc 2012;2012:173269.

38. Suzuki T, Hara T, Kitagawa Y, Yamaguchi T. Magnified endoscopic observation of early colorectal cancer by linked color imaging with crystal violet staining (with video). Gastrointest Endosc 2016;84:726-729. 